\title{
CREDIT, SOCIAL MENTALITY AND TECHNICAL INNOVATION
} EFFICIENCY

\section{Tingting Zhou}

Department of financial

management, Beijing

International Studies University. nkjanett@163.com(Tingting Zhou).

Dandan Hu

Westingarea Supply Chain Co., Ltd., Shanghai, China

\begin{abstract}
Existing literature has confirmed the importance of science and technology innovation on its promoting sustainable, healthy and rapid growth of the economy from the perspective of innovation forms, regional environment, and time phases, but the influence of social factors is neglected in the research of the efficiency of technology. Using provincial panel data during the period of 2000 to 2013, we probe into a path that improves the effects of science and technology innovation on economic growth from the perspective of the social environment rather than of pure technology. This study introduces social factors into the research model and takes account of credit construction and social mentality to explore the impact mechanism of science and technology innovation on economic growth. The results indicate that regional innovation activities remarkably improve the growth of the economy. The establishment of regional credit websites and the publication of honest and dishonest behavior dramatically improve the promoting effects of innovation on the economy. The positive social mentality can spread the "positive energy" through shared reality, inter-subjectivity consensus and social representation in the social interaction to promote technical innovation efficiency. The higher attention of regional netizens to stress, anxiety, indifference, anger, rich second generation, wealth showoff have negative impacts on the innovative activities and weaken the innovations' support to economic growth. This study suggests that regional governments strengthen the process of credit construction in the aspect of formulating credit policies and regulations, standardizing the credit information platform and credit service market, and finally establishing a sound social credit system. Besides, governments need to guide positive social mentality into the mainstream ideology of the society and pay attention to online public opinions to properly channel the negative emotions that hinder the healthy development of social mentality.
\end{abstract}

Keywords: Science and technology innovation efficiency; Creditconstructions; Social mentality

JEL Codes: O3, O1

| Received November 2019 | Accepted December 2019 | Available online December 2019 |

| DOI: http://dx.doi.org (Editor only)

\section{INTRODUCTION}

Technology innovation has a complex and dynamic impact on economic growth and tends to show differences due to innovation forms, regional environment and time 
phases. Independent innovation, technological diffusion via FDI and promotion of government-university-industry cooperation, to various extents, exert different influence on economic growth. Since the impact of technical innovation on regional economic development varies according to the degree of territorial development, it is important to analyze the characteristics of economic growth and feasible development modes based on different levels of scientific and technological progress among regions.

Except for innovation forms, regional environment and time phases, existing literatures have neglected a significant variable, namely social factor. Temple and Johnson (1998) state that social arrangement is an important factor affecting economic growth. Thus, economists' ignorance of social elements when they analyze driving factors of economy will lead to discrepancy between empirical prediction and actual economy. Generally, social factor, reflecting the prevalent, implicit and inherent state of a society, refers to value faith, ethics and morality, manners and customs and ideologies that impose extensive constraints on human behavior. Considering that social environment plays an important role in innovative progress of science and technology, the neglect of social factor in current studies might lead to inaccurate understanding of science and technology innovation efficiency. Therefore, based on the interprovincial panel data during the period of 2000 to 2013, this paper incorporates social factor and takes account of credit construction and social mentality to explore the impact mechanism of science and technology innovation on economic growth. We aim to improve the effect of science and technology innovation on economic growth from the perspective of social environment rather than of pure technology.

Explaining the problem's formulation should cover the following points: (1) Problem recognition and its significance; (2) clear identification of the problem and the appropriate research questions; (3) coverage of problem's complexity; and (4) welldefined objectives.

\section{LITERATURE REVIEW}

Empirical literature emphasizes the importance of science and technology in promoting economic growth. Both neoclassical economics growth theory and endogenous growth theory expound the contribution of technological advance on economic growth. However, the former believes that knowledge accumulation and technology belong to exogenous factors, the latter holds that technological progress is an endogenous factor in economic growth. Based on the Harrod-Domar growth mode, Solow (1956) introduces technological progress into his research model and finds that labor input, capital investment and productivity improvement following progress of science and technology could stimulate economic development. Romer(1986) presents the increasing-returns economic growth model, which took capital and labor into account and considered knowledge, especially technical change, endogenous production factor. Moreover, Lucas(1988) argues that economic growth is the result of human capital accumulation such as knowledge accumulation and advanced technical proficiency. In short, Romer(1986) and Lucas (1988) represent the new economic growth theory regarding technical progress as an endogenous factor that impacts economic growth, and indicate that economic growth is derived from technological change within economic systems.

In terms of empirical research, scholars carry out immense amount of research studying the relationship between scientific and technological progress and economic growth.

212 Management and Economics Journal (MEC-J)

Vol 3 (3) December 2019 
Most of these literatures confirm the importance of science and technology innovation. Science and technology are the primary productive forces. Chinese government is paying more and more attention on the technology (Greeven, 2004; Zhang et al., 2008). Technical innovation suitability has a great contribution to economic growth in Chinese 31 provinces (Zhou et al., 2012). Fan et al. (2017) hold the idea that there is a significant positive relationship between the innovation and the economic growth in the mineral extractive industry and the electricity, heat, gas and water production and supply industry. More specifically, in labor intensive state-owned sector or capital-intensive mixed sector, the more the government research support is and the higher the technical assets rate is, the greater progress the economic growth will make. Xie(1999) notes that if the subsidy to basic research was reduced, the speed of technological process will be lower. As a result, there will be a lower rate of economic growth. Using Cobb-Douglas production function, Yuan et al. (2014) find that China's defense industry innovation has positive effects on economic growth.

Kanygin (1976) emphasizes that science, which is viewed as autonomous production factor, has a profound impact on the economic growth. In the view of Weng et al. (2012), technological improvements play a great more important role in pushing the economy forwards, which requests a higher level of technology in turn. Shan et al. (2018) mention that the average GDP growth in China from 2010 to 2014 created by technological entrepreneurship is up to $41.49 \%$. Caves (1974) find that FDI technology spillover has positive effects on the economic growth in in Canada and Australia. Scientific and technological development functions as the core element to promote sustainable, healthy and rapid growth of economy. Ding and $\mathrm{Li}$ (2013) present that Chinese continuous fast growth is the result of institutional innovation, FDI, as well as the technological innovation. Guo et al. (2012) use a new method by mixing the soft computing approach, the Cobb-Douglas production and the Solow residual value method to explore the relationship between the scientific and technological progress and the economic growth in thirty one regions of China from the year of 1998 to 2007, and they came to the conclusion that the growth of regional economy mainly depended on the scientific and technological progress and capital investment. According to Leser's (1967), technological innovation is the driving force of economic development in Germany and advance in technology takes a more and more important role in the economic growth process.

Technology, which includes the technical innovation, as well as organizational or disembodied innovation, should be emphasized in the economic growth (Sanidas, 2004). Specifically, adding R\&D input and increasing transformation efficiency of scientific and technological achievements will provide a sustained impetus to economy. Weng et al. (2012) indicate that patent as the output of science and technology has a strong positive effect on the economic growth in Shanghai. Based on Solow residual method, Zhuo et al. (2015) analyze the contribution rate of the scientific and technological progress to economic growth in coal enterprise, and find that the rate can be achieved at $36.06 \%$. The contribution of science and technology to economic growth is also reflected in the improvement of economic growth efficiency and the transition of economic growth pattern. We therefore make the following hypothesis 1.

Hypothesis 1. Regional science and technology innovation have significantly promoted steady growth of regional economy. 
Credit underlie the following discussion of the mechanism on how credit construction contributes to science and technology innovation. Hence, this paper clarifies the definition of credit prior to theoretical analysis. The Modern Chinese Dictionary gives the following definition of "credit": (1) trust gained by honoring agreements with others; (2) no need to provide material guarantees because someone can pay on time; (3) an arrangement with a shop or bank that allows later payment. The first explanation of credit, in a broad sense, indicates that credit is the trust achieved by participants who keep promises and engagements in social and economic activities at the sociological and ethical level. Honesty is a moral constraint to individuals and a theoretical basis for establishing credit relationship. In a narrow sense, the second and third definitions suggest that credit, at the economic and financial level, is a special form of value movement in which the participants of the market economy are conditioned to repayment. The explanation of credit in CiHai is presented in the following: (1) to appoint someone with trust; (2) to observe and keep promises in order to gain trust from others; (3) a special form of value movement conditional on reimbursement, which is common in monetary lending and sales on account or prepayment in transactions. It often appears as business credit, bank credit, state credit and consumption credit. The first and second definitions of credit in CiHai bear a broad sense, similar to the first definition of credit from the Modern Chinese Dictionary. And the third definition is in a narrow sense, near to the second and third descriptions of credit in the Modern Chinese Dictionary. In this paper, we discuss a broad sense of credit.

From the perspective of credit construction at the national level, the establishment of a credit system is conducive to the healthy, coordinated and stable development of the market economy. However, lack of credit will result in wasting social resources and weakening the competitiveness of Chinese economy in the world. Credit economy, on the basis of honesty, develops economic activities such as production, distribution, exchange and consumption. Reasonable credit scale, credit structure and the development of credit economy could increase social and economic benefits. On the whole, a favorable credit relationship is beneficial to promote the understanding and trust within social groups and reduce unnecessary transaction costs in economic activities.

From the angle of trust among individuals in economic life, law and trust could maintain the orderly operation of the market economy, reduce transaction costs, loose market regulations and encourage investors to participate in investment activities, and thus facilitate the prosperity and development of the capital market. However, in a social environment with low levels of trust, people tend not to invest in capitalmarket and consequently slow down the pace of economic growth. Putnam et al. (1994) state that trust or social capital encourages people to work together to improve social efficiency and avoid the lack of inefficiency in cooperation.

The construction of an overall social credit system and cultivation of individuals' credit recognition are crucial to improve the efficiency of science and technology innovation. Especially, the establishment of credit regulations in a credit system could provide individuals with credit standards and guidelines, and implement restricts on individuals' behavior in economic life. Cultivating residents' comprehensive understanding of credit concept could favor the implementation of credit rules, regulations and laws, and accordingly increase the overall social credibility. Since R\&D innovation plays a remarkable role in social and economic activities, credit construction could be conducive 
to stimulating science and technology innovation, improving the awareness of honesty among researchers, encouraging them to actively carry out independent innovation instead of copying and plagiarizing others' scientific and technological achievements, prompting researchers to make reasonable use of limited scientific and technological resources, increasing the quality and efficiency of innovation, and making efforts to enhance the positive impact of science and technology innovation on economic growth.

Hypothesis 2. The boosting effect of science and technology innovation on economic growth is more obvious in regions with good credit construction.

Social mentality reflects the psychological state of the whole society in terms of social value orientation, social emotion and social cognition, which are under certain influence of social, economic and cultural environment in a period of time. Positive social mentality, such as "trust", "equality", "happiness", etc., can convey "positive energy" to the whole society and are conducive to the harmony and stability of society, thus providing a good social environment for economic development. On the contrary, negative social mentality such as "anger", "anxiety" and "indifference" accelerates the transmission of "negative energy" and weakens the enthusiasm of social groups. The negative mood will not only affect the individuals' mental health, but also lay a hidden danger for the steady development of the economy and society. Social mood is a manifestation of contradictions and conflicts in the transformation of Chinese society. Even though the overall tone of social mood is still positive, the current situation of negative emotion is not that optimistic. Especially, in the era of new media, since people can get the latest information in real time through various news media or mobile phone applications, public opinions could spread quickly on the Internet and lead to intensive discussions of social issues. Therefore, overcoming negative social mentality and guiding the development of social mentality to a correct, positive and healthy direction are crucial to China's economic construction.

For the specific formation process of social mentality, we can borrow ideas from psychological theories such as shared reality, inter-subjectivity consensus and social representation. Specifically, inter-subjectivity consensus is an extension of the shared reality theory and both emphasize the importance of individual understanding of others' values on establishing a common internal state within social groups. The social representation theory indicates that individuals gradually become familiar with unacquainted knowledge in social interaction. Particularly, the dominant representation therein presents that mainstream values and ideology have exemplary, dominant and leading effects on ordinary people. Consequently, it is necessary to guide the positive social mentality into the mainstream ideology of the society according to the dominant representation theory. The mainstream social consciousness can form a correct demonstration and guidance for the formation of cognition and values of ordinary people, and allow social groups to reach an internal consensus on the mainstream values of the society. The consensus requires that groups and individuals in social interaction be self-disciplined and regulated, and that form intangible external supervision of groups and individuals in social interaction through its generally accepted characteristics.

Social mentality takes a guiding role in individual behavioral motivation. The results of human activities are constrained by two factors -- ability and motivation. And an appropriate motivation is beneficial to improve work efficiency. In social life, advocating positive philosophy of life such as caring for family, living in harmony, being honest and 
trustworthy, being fair and just, and respecting beliefs, etc., will cultivate active cognition and values among social groups in an overall environment. Since individuals are apt to establish a common internal state in social interaction with reference to other people's social behavior, positive social mentality will allow the mentality of social groups to develop in a right direction and provide a correct reference for individuals holding negative social mentality. For R\&D personnel, an active social attitude will be formed under the impact of active mainstream social mentality. And the positive mentality among individuals is expressed by positive attitudes of life and efficient work experience of R\&D personnel. The positive social mentality of R\&D personnel is advantageous to create a good R\&D work environment, improve the efficiency and effectiveness of R\&D activities, and reduce mistakes caused by negative mentality at work. Hence, the improvement of efficiency in R\&D innovation activities and fewer work errors can promote a rational use of scientific and technological resources, improve the output benefit and economic benefit of R\&D investments, and increase the contribution rate of innovation activities to economic growth. A harmonious family and working environment and efficient work created by positive social mentality will further enhance the recognition of social groups and their supports for the mainstream social mentality, form a virtuous circle among social mentality, social environment and work efficiency, and accelerate the driving force of technological innovation to economic growth.

Hypothesis 3. For regions which have higher level of regional social mentality, the positive relationship between technological innovation and economic growth is more obvious.

\section{METHOD}

\section{Data, Sample and Variables}

From the perspective of credit construction and social mentality, this paper adopts provincial panel data from 2000 to 2013 to explore the influence mechanism of science and technology innovation on economic growth. The data on economic development and science and technology innovation are derived from the China Statistical Yearbook and the China Statistical Yearbook of Science and Technology, respectively. Credit data originates from the official credit websites of provinces and municipalities. Data on social mentality are obtained from Baidu Index and CGSS (Chinese General Social Survey).

This study adopts provincial data on science and technology innovation from 2000 to 2013. To identify the influence mechanism of science and technology innovation on regional economic growth from the perspective of credit construction and social mentality, we estimate the following regression:

$$
\begin{aligned}
\text { PERGDP }_{i t} & =h+q_{1} \text { LTECH }_{i, t-1}+q_{2} \text { SOCF }_{i t}+q_{3} \text { LTECH }_{i, t-1}{ }^{\prime} \\
& \text { SOCF }_{i t}+q_{4} P E R C A P_{i t}+q_{5} \text { INDUS }_{i t}
\end{aligned}
$$

Where, we employ PERGDP to portray the economic development of regions, which is measured by real GDP per capita of regions. The real GDP, taking the year of 2000 as base period, is deflated according to the price index of each year. The science and technology innovation index (LTECH) is a comprehensive index calculated by principal component analysis of 18 indicators in five dimensions: $R \& D$ innovation investment 
(expenditure on new products development), R\&D innovation scale (number of new products), non-R\&D innovation investment (expenditure for acquisition of foreign technology, assimilation of technology, purchase of domestic technology and technical renovation), intermediate output (number of patent applications, inventions applications, inventions in force, accepted inventions, accepted utility models, accepted designs, granted inventions, granted utility models and granted designs), and scientific and technological achievements transformation (sales revenue of new products, output value of new products, transaction value in technical markets by region). In view of the periodicity of technological innovation and the time lag of input and output, there will be a certain lag period for the impact of science and technology innovation on economic growth. Considering the endogeneity between science and technology innovation and economic growth, we use lagged one-year data of the science and technology innovation index $(\mathrm{LTECH})$. $\mathrm{i}$ and $\mathrm{t}$ represents region and year distinctly. SOCF characterizes credit construction (CREDIT) and social mindset (SCMIND) variables.

CREDIT is the credit construction variable, including the establishment of credit websites (ESTAB), credit news (AFFAIR), credit policy (POLICY), credit publicity (HONE, DIHONE). The CREDIT data is collected manually from the information published on local credit websites. ESTAB is a dummy variable with value of one if a province establishes its credit websites, and zero otherwise. The calculation formula of credit news (AFFAIR) is LN $(1+A F I R)$, and AFIR is the number of credit news published on each local credit website each year. POLICY measures the number of national and local credit policies released on local credit websites. Besides,credit publicity includes the publicity of trustworthy behavior (HONE) and the disclosure of untrustworthy behavior (DIHONE), whose processing methods are similar to credit news.

Generally, trustworthy behavior mainly embraces enterprises' paying tax by credibility, food safety, engineering safety, and individuals' abiding by professional ethics and insisting on repayment of debts; untrustworthy behavior covers non-compliance with traffic rules, harming social security, malicious frauds, and cheating in national exams. For example, the credit publicity section of Fujian Credit Website "Credit Fujian" is divided into good information and warning information. Both types of information are interconnected among administrative organs such as Fujian Development and Reform Commission, Fujian Provincial Public Security Department, Fujian Provincial Department of Transportation and Fujian Food and Drug Administration, allowing viewers to obtain comprehensive credit information. According to the release time of credit news, Hunan province established the earliest credit website "Credit Hunan" among 31 provinces, municipalities and autonomous regions in China. Statistically, 14 provinces, municipalities and autonomous regions have not established credit websites until the year of 2013. In July 2016, however, all provinces, municipalities and autonomous regions have established credit websites. Local credit websites that have been well established generally publish real-time credit news, credit policies, and credit publicity.

SCMIND symbolizes social mentality variable that includes both positive and negative social mentality. ACTIVE characterizes positive social mentality, covering data on equity (EQUITY), happiness (HAPINS), faith (FAITH)from Baidu Index and statistics for equity (EQUAL), happiness (HAPPY), and trust (TRUST) from CGSS. PASSIVE portrays negative social mentality, incorporating information of stress (STRESS), gloom (GLOOM), anxiety (ANXIETY), indifference (INDIFER), quick success (QBENFT), anger (ANGER), the rich second generation (RCSCGN), behavior of flaunting wealth (SHOWOF), gorgeous 
millionaires (GFS), wealthy belle (FUMBLA) and competition of family background (DADKY) captured from Baidu Index.

Baidu Index is a data sharing platform built on netizens' search behavior of websites and news on Baidu search engine. With the rapid development of the Internet, the scale of Internet users continues to expand. The search engine is used as a basic Internet application, whose usage rate ranks second only to real-time communication. As the world's largest Chinese search engine, Baidu is the most frequently used search site for Chinese Internet users. The online search behavior of local net citizens on certain issues can indirectly reflect the psychological state of people in that area. We customize time buckets and regions on the websites of Baidu Index to look up the Index Trend of certain keywords to obtain their overall trend, trend on PC and trend on mobile end system. Finally, this paper takes the overall average trend of the "keywords" of social mentality from Baidu Index in each region per year as a proxy variable to measure regional social mentality. The data range from 2011 to 2013, since Baidu Index began to provide data in 2011. And the data from Baidu Index are crawled from its official websites through the Crawler plus ocr program developed by Python.

Taking the variable equity (EQUITY) of positive social mentality as an example, we capture the daily data of integrative trend on "equity" from 31 provinces, municipalities and autonomous regions in China from the official websites of Baidu Index. According to the regional and annual statistics for the average annual comprehensive trend of keyword "equity" (EQUI), this study calculates the variable EQUITY with the formula of LN(1+EQUI). A high value of EQUITY means that regional Internet users are paying highly attention to the issue of "equity", to a certain extent, representing positive social mentality in the aspect of equity. The rest of the social mentality variables from the Baidu Index are treated similarly to EQUITY. For negative social mentality variables, the larger the value is, the more negative the social mentality of the region maintains.

Social mentality data are also taken from CGSS. The authors read the CGSS questionnaires in detail and select three types of survey questions reflecting "happiness", "equality" and "trust" to construct positive social mentality variables. Here take happiness (HAPPY) as an example to introduce its assignment rule according to the answers to happiness-related questions. We assign "very unhappy", "unhappy", "ordinary", "happy" and "very happy" a value of 1, 2, 3, 4, and 5, respectively. And the HAPPY variable was obtained from regional and annual average value of "respondents' happiness". Higher value of HAPPY indicates stronger happiness of respondents in regions. Additionally, EQUAL and TRUST variables are treated like HAPPY so that the following only briefly describes their assignment rules: "completely unequal" and "very mistrustful" are valued at 1; "unequal" and "mistrustful" are 2, "normal" and "general" are 3; "comparative equal" and "trustful" are 4; and the "completely equal" and "very trustful" are 5. Due to the accessibility of data, the data on happiness (HAPPY) range in 2003, 2005, 2006, 2008, 2010, 2011, 2012 and 2013 from CGSS; the statistics for equality (EQUAL) is in 2003, 2005, 2010, 2011, 2012 and 2013; trust (TRUST) variable covers the data in the year of 2003, 2010, 2011, 2012 and 2013.

Based on the existing literature, we use the following variables as control variables to capture the determinants of economic growth. PERCAP represents material capital per capita, measured by the ratio of material capital stock to quantity of labor force. The estimation of capital stock in each region is calculated by the perpetual inventory 
method, and the formula is Kit $=$ lit $+(1-\delta) \times \mathrm{Ki}, \mathrm{t}-1 . \mathrm{K}$ represents the capital stock and I indicates the gross fixed capital formation, which is deflated according to the fixed asset investment price index or commodity consumer price index for the same period when there is missing value of fixed asset investment price index. The value of $\delta$ is $9.6 \%$. INDUS measures industrial structure, which reflects the proportion of employees in tertiary industry to the total number of employment. FORNT is foreign trade dependence, which shows the proportion of gross imports and exports to GDP. GOVMODL reflects government-scale and is measured by the ratio of government expenditure to GDP. COLLSTD is the number of college students per 10,000 people. YEAR is the annual dummy variable.

\section{RESULTS}

\section{Empirical Results:}

\section{Descriptive Statistics:}

Table 1 presents the descriptive statistic. The average value of PERGDP is 1.885 and the average value of science and technology innovation index (LTECH) is 0.0002 . Within the sample spacing, on average $21.2 \%$ of the regions establish credit websites. And regional credit websites post an average of about 827 piece of credit news (AFFAIR), whose nature logarithm is 5.294. The average number of credit policies (POLICY), trustworthy behavior (HONE), and untrustworthy behavior (DIHONE) published on local credit websites were about 20, 67 and 26, whose nature logarithm is 2.121, 2.939, and 2.614, respectively.

The mean values of positive social mentality variables (EQUITY, FAITH, HAPINS) from the Baidu Index are 3.614, 4.762, and 4.358, distinctly. Before taking logarithm, the average values are $45.651,149.387$ and 98.765 , indicating that local netizens pay more attention to "faith" and "happiness" than "equity". The mean values of positive social mentality variables (HAPPY, TRUST, EQUAL) from CGSS are 3.594, 3.176, and 3.185. Relative to the lowest value of 1 and highest value of 5 , the data show that respondents are located in the state of "between happiness and unhappiness", "general trust", and "between fairness and unfairness".

The mean values of negative social mentality (STRESS, GLOOM, ANXIETY, INDIFER, QBENFT and ANGER) are 4.127, 4.027, 3.735, 4.695, 3.255 and 3.916. The average corresponding values before taking nature logarithms are 71.411, 64.629, 52.902, 151.153, 32.595 and 59.733. These data show that the local Internet users pay the highest attention to "indifference" and "stress", and the lowest attention to "quick success" and "anxiety". From the angle of rich second generation, the average values of the rich second generation (RCSCGN), behavior of flaunting wealth (SHOWOF), gorgeous millionaires (GFS), wealthy belle (FUMBLA), and competition of family background (DADKY) are 4.253, 3.692, 4.195, 4.187 and 3.488. And the mean values before resulting nature logarithm are $96.185,52.051,97.920,90.921$ and 39.794, respectively, indicating that the local netizens pay high attention to "rich second generation", "gorgeous millionaires" and "wealthy belle". The average material capital stock per capita (PERCAP) is 1.533 billion RMB per person. The average ratio of employment in the tertiary industry in the region to the total employment (INDUS) is $33.2 \%$. The regional gross import and export volume and government expenditure accounted for $32.2 \%$ and $20.8 \%$ of the regional GDP respectively. And there is an average of 103 college students per 10,000 people in the sample areas. 
Table 1. Descriptive Statistics

\begin{tabular}{lccclccc}
\hline Variables & Mean & Median & STD & Variables & Mean & Median & STD \\
\hline PERGDP & 1.885 & 1.367 & 1.650 & GLOOM & 4.027 & 4.256 & 0.810 \\
LTECH & 0.0002 & -0.917 & 2.896 & ANXIETY & 3.735 & 4.113 & 1.000 \\
ESTAB & 0.212 & 0.000 & 0.409 & INDIFER & 4.695 & 4.964 & 1.073 \\
AFFAIR & 5.294 & 5.974 & 2.269 & QBENFT & 3.255 & 3.551 & 0.934 \\
POLICY & 2.121 & 1.946 & 1.301 & ANGER & 3.916 & 4.228 & 0.915 \\
HONE & 2.939 & 2.639 & 1.390 & RCSCGN & 4.253 & 4.594 & 1.065 \\
DIHONE & 2.614 & 2.398 & 1.087 & SHOWOF & 3.692 & 4.148 & 0.964 \\
EQUITY & 3.614 & 3.951 & 0.991 & GFS & 4.195 & 4.536 & 1.132 \\
FAITH & 4.762 & 4.982 & 0.933 & FUMBLA & 4.187 & 4.596 & 1.085 \\
HAPINS & 4.358 & 4.527 & 0.984 & DADKY & 3.488 & 3.746 & 0.934 \\
HAPPY & 3.594 & 3.656 & 0.354 & PERCAP & 15.330 & 9.836 & 20.586 \\
TRUST & 3.176 & 3.360 & 0.522 & INDUS & 0.332 & 0.320 & 0.101 \\
EQUAL & 3.185 & 3.081 & 0.398 & FORNT & 0.322 & 0.130 & 0.408 \\
STRESS & 4.127 & 4.334 & 0.863 & GOVNMODL & 0.208 & 0.169 & 0.159 \\
\hline
\end{tabular}

Authors must provide high quality artwork for all illustrations. Poor resolution or definition is not acceptable. All tables and figures (graphs) should be included directly in the appropriate part of the article (not separated). Each table or figure should be numerically numbered separately (Table 1, Table 2; Figure 1, Figure 2) and fully titled, which refers to the contents of the table or figure. Underneath each table and figure, state the reliable source. Use only horizontal lines, 1.5 spaced

Table 2 presents the regression results of the relationship among science and technology innovation, credit construction and economic growth. Technology innovation (LTECH) is positively and significantly associated with economic growth (PERGDP), validating hypothesis 1. The estimated coefficient on ESTAB is significantly positive, indicating that regions hold a relatively good credit construction generally perform well in establishing credit websites, which would promote the growth of regional economy. However, the estimated coefficients on AFFAIR and POLICY are not significantly positive. And the estimated coefficient on trustworthy behavior (HONE) is significantly positive, while the estimated coefficient on untrustworthy behavior (DIHONE) is significantly negative. The regression results show that trustworthy behavior can provide a good demonstration for the public, help to improve people's credit awareness, and promote regional economic growth. Accordingly, untrustworthy behavior in the society would have negative impacts on economic growth.

The estimated coefficient on the interaction term between LTECH and ESTAB is significantly positive, while the estimated coefficients on the interaction terms between LTECH and credit publicity variables (HONE and DIHONE) are both significantly negative. 
And the estimated coefficients on the interaction terms between LTECH and credit news (AFFAIR), credit policy (POLICY) are not significant. The regression results suggest that the establishment of regional credit websites and the publicity of trustworthy behavior and untrustworthy behavior play important roles in regional credit construction, which is conducive to enhancing the credit awareness of social groups and promoting the effect of science and technology innovation on economic growth. Furthermore, the improvement of overall credit conditions of the society is beneficial to encourage R\&D personnel to exert independent innovations, improve the efficiency of science and technology innovation, and exert full efforts to develop potentials of regional science and technology innovation environment in promoting the stable growth of regional economy. On the contrary, credit violations brought about by untrustworthy behavior in the society will entice some groups to pursue merely interests. For example, in innovation activities, the R\&D personnel would plagiarize the results of others and provide false reports on $R \& D$ results, destroying the boosting effect of science and technology innovation on economic growth to some extent.

Table 2 . Science and technology innovation, Credit Construction, Economic Growth

\begin{tabular}{|c|c|c|c|c|c|c|}
\hline & (1) & (2)ESTAB & (3)AFFAIR & (4)POLICY & (5)HONE & (6)DIHONE \\
\hline$C$ & $\begin{array}{l}-0.828^{* * *} \\
(-2.606)\end{array}$ & $\begin{array}{l}-0.524^{*} \\
(-1.725)\end{array}$ & $\begin{array}{l}-0.575^{* *} \\
(-1.961)\end{array}$ & $\begin{array}{l}-0.506 \\
(-1.648)\end{array}$ & $\begin{array}{l}-0.518^{*} \\
(-1.773)\end{array}$ & $\begin{array}{l}-0.530^{*} \\
(-1.767)\end{array}$ \\
\hline LTECH & $\begin{array}{l}0.024^{* *} \\
(2.251)\end{array}$ & $\begin{array}{l}0.025^{* *} \\
(2.389)\end{array}$ & $\begin{array}{l}0.061^{* * *} \\
(4.024)\end{array}$ & $\begin{array}{l}0.028^{* *} \\
(2.493)\end{array}$ & $\begin{array}{l}0.048^{* * *} \\
(3.478)\end{array}$ & $\begin{array}{l}0.041^{* * *} \\
(3.356)\end{array}$ \\
\hline CREDIT & & $\begin{array}{l}0.923^{*} \\
(1.871)\end{array}$ & $\begin{array}{l}1.464 \\
(1.522)\end{array}$ & $\begin{array}{c}0.258 \\
(0.407)\end{array}$ & $\begin{array}{l}1.237^{* * *} \\
(2.985)\end{array}$ & $\begin{array}{l}-0.108^{* * *} \\
(-4.169)\end{array}$ \\
\hline LTECH $\times$ CREDIT & & $\begin{array}{l}1.157^{* *} \\
(2.249)\end{array}$ & $\begin{array}{l}-0.002 \\
(-0.507)\end{array}$ & $\begin{array}{c}0.323 \\
(0.657)\end{array}$ & $\begin{array}{l}1.005^{* * *} \\
(2.583)\end{array}$ & $\begin{array}{l}-0.173^{* * *} \\
(-4.839)\end{array}$ \\
\hline PERCAP & $\begin{array}{l}0.010^{* * *} \\
(6.668)\end{array}$ & $\begin{array}{l}0.010^{* * *} \\
(6.417)\end{array}$ & $\begin{array}{l}0.007^{* * *} \\
(6.453)\end{array}$ & $\begin{array}{l}0.010^{* * *} \\
(6.612)\end{array}$ & $\begin{array}{l}0.010^{* * *} \\
(7.202)\end{array}$ & $\begin{array}{l}0.010^{* * *} \\
(6.639)\end{array}$ \\
\hline INDUS & $\begin{array}{l}3.294^{* * *} \\
(4.185)\end{array}$ & $\begin{array}{l}2.347^{* * *} \\
(3.156)\end{array}$ & $\begin{array}{l}2.540^{* * *} \\
(3.373)\end{array}$ & $\begin{array}{l}2.328^{* * *} \\
(3.098)\end{array}$ & $\begin{array}{l}2.446^{* * *} \\
(3.317)\end{array}$ & $\begin{array}{l}2.442^{* * *} \\
(3.262)\end{array}$ \\
\hline FORNT & $\begin{array}{l}1.585^{* * *} \\
(12.365)\end{array}$ & $\begin{array}{l}1.597^{* * *} \\
(12.174)\end{array}$ & $\begin{array}{l}1.665^{* * *} \\
(11.629)\end{array}$ & $\begin{array}{l}1.591^{* * *} \\
(11.622)\end{array}$ & $\begin{array}{l}1.525^{* * *} \\
(11.979)\end{array}$ & $\begin{array}{l}1.540^{* * *} \\
(11.919)\end{array}$ \\
\hline GOVMODL & $\begin{array}{l}-1.000^{* * *} \\
(-5.121)\end{array}$ & $\begin{array}{l}-0.909^{* * *} \\
(-4.945)\end{array}$ & $\begin{array}{l}-0.683^{* * *} \\
(-3.438)\end{array}$ & $\begin{array}{l}-0.898^{* * *} \\
(-4.957)\end{array}$ & $\begin{array}{l}-0.819^{* * *} \\
(-4.491)\end{array}$ & $\begin{array}{l}-0.840^{* * *} \\
(-4.509)\end{array}$ \\
\hline COLLSTD & $\begin{array}{l}-0.0001^{* * *} \\
(-2.694)\end{array}$ & $\begin{array}{l}-0.0001^{* * *} \\
(-3.983)\end{array}$ & $\begin{array}{l}-0.0001^{* * *} \\
(-2.348)\end{array}$ & $\begin{array}{l}-0.0001^{* * *} \\
(-3.772)\end{array}$ & $\begin{array}{l}-0.0001^{* * *} \\
(-3.420)\end{array}$ & $\begin{array}{l}-0.0001^{* * *} \\
(-3.423)\end{array}$ \\
\hline YEAR & YES & YES & YES & YES & YES & YES \\
\hline $\operatorname{Adj} . R^{2}$ & 0.875 & 0.862 & 0.886 & 0.862 & 0.872 & 0.866 \\
\hline$F$ & $138.010^{* * *}$ & $137.808^{* * *}$ & $153.396^{* * *}$ & $123.264^{* * *}$ & $135.289^{* * *}$ & $127.668^{* * *}$ \\
\hline$N$ & 394 & 394 & 394 & 394 & 394 & 394 \\
\hline
\end{tabular}

Note: ***,**, or * indicates that the coefficient estimate is significant at the $1 \%, 5 \%$, or $10 \%$ level, respectively. 
Table 3. Science and technology innovation, Positive Social Mentality and Economic Growth

\begin{tabular}{|c|c|c|c|c|c|c|}
\hline & (1)EQUITY & (2)HAPINS & (3)FAITH & (4)EQUAL & (5)HAPPY & (6)TRUST \\
\hline \multirow[t]{2}{*}{$C$} & $0.563^{* * *}$ & $0.907^{* * *}$ & $0.784^{* * *}$ & -1.196 & 0.695 & 1.718 \\
\hline & (11.703) & $(14.195)$ & (15.021) & $(-1.278)$ & $(1.197)$ & $(1.629)$ \\
\hline \multirow[t]{2}{*}{ LTECH } & $0.039^{* * *}$ & $0.069^{* * *}$ & $0.055^{* * *}$ & $0.008^{* * *}$ & $0.004^{* *}$ & $0.010^{* * *}$ \\
\hline & $(7.114)$ & $(6.522)$ & $(7.080)$ & $(4.801)$ & $(1.993)$ & $(8.802)$ \\
\hline \multirow[t]{2}{*}{ ACTIVE } & $0.050^{* * *}$ & $1.197^{*}$ & $0.013^{*}$ & $0.740^{* * *}$ & $0.370^{* *}$ & 0.034 \\
\hline & $(2.756)$ & $(1.784)$ & $(1.800)$ & $(4.909)$ & $(2.090)$ & $(0.103)$ \\
\hline \multirow[t]{2}{*}{ LTECH $\times$ ACTIVE } & $1.898^{* * *}$ & $1.744^{* * *}$ & $0.801^{* *}$ & $0.003^{* * *}$ & $0.003^{* *}$ & $2.348^{* * *}$ \\
\hline & $(7.883)$ & $(5.472)$ & $(2.457)$ & $(8.323)$ & (1.973) & (3.870) \\
\hline \multirow[t]{2}{*}{ PERCAP } & $0.001^{* * *}$ & $0.001^{* * *}$ & $0.001^{* * *}$ & $0.003^{*}$ & $0.003^{* *}$ & $0.003^{*}$ \\
\hline & (3.697) & $(2.946)$ & $(3.545)$ & $(1.904)$ & (1.973) & $(1.840)$ \\
\hline \multirow[t]{2}{*}{ INDUS } & $0.657^{* * *}$ & $0.585^{* * *}$ & $0.172^{* * *}$ & 1.648 & $1.352^{* * *}$ & $2.188^{* *}$ \\
\hline & $(7.898)$ & $(6.226)$ & $(5.668)$ & $(1.421)$ & (3.230) & $(2.011)$ \\
\hline \multirow[t]{2}{*}{ FORNT } & $0.814^{* * *}$ & $0.880^{* * *}$ & $0.913^{* * *}$ & $1.536^{* * *}$ & $1.215^{* * *}$ & $0.891^{* * *}$ \\
\hline & $(25.185)$ & $(47.973)$ & $(24.372)$ & $(7.960)$ & $(10.118)$ & $(6.049)$ \\
\hline \multirow[t]{2}{*}{ GOVMODL } & $-0.766^{* * *}$ & $-0.907^{* * *}$ & $-0.916^{* * *}$ & -0.223 & $-0.349^{* *}$ & $-0.326^{*}$ \\
\hline & $(-11.944)$ & $(-7.391)$ & $(-42.571)$ & $(-1.570)$ & $(-2.087)$ & $(-1.782)$ \\
\hline \multirow[t]{2}{*}{ COLLSTD } & $-0.0001^{* * *}$ & $-0.0001^{* * *}$ & $-0.0001^{* * *}$ & -0.00003 & 0.00003 & 0.00002 \\
\hline & $(-27.766)$ & $(-156.055)$ & $(-33.915)$ & $(-1.055)$ & $(0.880)$ & $(0.411)$ \\
\hline YEAR & YES & YES & YES & YES & YES & YES \\
\hline Adj. $R^{2}$ & 0.851 & 0.876 & 0.926 & 0.797 & 0.827 & 0.780 \\
\hline$F$ & $50.086^{* * *}$ & $61.937^{* * *}$ & $109.028^{* * *}$ & $54.618^{* * *}$ & $71.041^{* * *}$ & $41.176^{* * *}$ \\
\hline N & 87 & 87 & 87 & 165 & 221 & 137 \\
\hline
\end{tabular}

Note: ***, **, or * indicates that the coefficient estimate is significant at the $1 \%, 5 \%$, or $10 \%$ level, respectively.

Table 3 presents the regression results of the relationship among science and technology innovation, positive social mentality and economic growth. The estimated coefficients on HAPINS, HAPPY and FAITH are significantly positive, while the estimated coefficients on TRUST is not significantly positive, indicating that positive social mentality contributes to create a good social mood, build a harmonious social environment and thus provide the soft power for economic growth. The estimated coefficients on the interaction terms between LTECH and four negative social mentality variables (EQUITY, EQUAL, HAPIN, TRUST, FAITH and HAPPY) are significantly positive. The regression results demonstrate that through the sharing of reality, inter-subjectivity consensus and the characteristics of social representation, positive social mentality enables social groups to reach a common internal state, which gradually becomes the 
mainstream mentality of the society and provides overall society with guidance, regulations and supervisions to promote the efficiency of science and technology innovation. Practices show that positive social mentality has undergone qualitative change in the process of gradual accumulation, and has been transformed into broader and universal social sentiments, which would guide R\&D personnel to maintain a positive psychological state, provide a harmonious external environment for science and technology innovation activities, and then improve the efficiency of technical research.

Table 4 Science and technology innovation, Negative Social Mentality and Economic Growth: Individual Perspective on Negative Emotions

\begin{tabular}{|c|c|c|c|c|c|c|}
\hline & (1)STRESS & (2)GLOOM & (3)ANXIETY & (4)INDIFER & (5)QBENFT & (6)ANGER \\
\hline \multirow[t]{2}{*}{ C } & $1.119^{* * *}$ & $0.908^{* * *}$ & $0.663^{* * *}$ & $0.450^{* * *}$ & $0.409^{* * *}$ & $0.695^{* * *}$ \\
\hline & $(29.675)$ & (16.119) & $(13.655)$ & (3.359) & $(15.096)$ & $(23.882)$ \\
\hline \multirow[t]{2}{*}{ LTECH } & $0.024^{* * *}$ & 0.013 & $0.026^{* * *}$ & $0.060^{* * *}$ & $0.004^{* * *}$ & $0.029^{* * *}$ \\
\hline & $(4.586)$ & $(0.065)$ & $(6.120)$ & $(2.812)$ & (3.153) & $(3.388)$ \\
\hline \multirow[t]{2}{*}{ PASSIVE } & $-0.004^{* * *}$ & $-0.003^{* * *}$ & $-0.003^{* * *}$ & -0.0002 & $-0.001^{* * *}$ & $-0.002^{* * *}$ \\
\hline & $(-7 \cdot 553)$ & $(-5.444)$ & $(-5.490)$ & $(-0.642)$ & $(-3 \cdot 321)$ & $(-9 \cdot 918)$ \\
\hline \multirow[t]{2}{*}{ LTECH $\times$ PASSIVE } & $-0.0001^{* * *}$ & -0.0001 & $-0.0003^{* * *}$ & $-0.0001^{* * *}$ & $0.00002^{*}$ & $-0.0002^{* * *}$ \\
\hline & $(-2.796)$ & $(0.1004)$ & $(-7.329)$ & $(-3.600)$ & $(-1.771)$ & $(-3.467)$ \\
\hline \multirow[t]{2}{*}{ PERCAP } & $0.001^{* * *}$ & $0.001^{* * *}$ & $0.001^{* * *}$ & $0.001^{* * *}$ & $0.001^{* * *}$ & $0.001^{* * *}$ \\
\hline & (3.873) & $(0.0002)$ & $(4.059)$ & (3.123) & $(4.686)$ & $(4.004)$ \\
\hline \multirow[t]{2}{*}{ INDUS } & $0.191^{* * *}$ & $0.274^{* * *}$ & $0.664^{* * *}$ & $0.599^{* * *}$ & $0.719^{* * *}$ & $0.603^{* * *}$ \\
\hline & $(3.573)$ & $(6.521)$ & $(7.139)$ & $(16.603)$ & $(11.850)$ & $(11.005)$ \\
\hline \multirow[t]{2}{*}{ FORNT } & $0.984^{* * *}$ & $0.941^{* * *}$ & $0.834^{* * *}$ & $0.756^{* * *}$ & $0.828^{* * *}$ & $0.821^{* * *}$ \\
\hline & $(25.850)$ & $(20.554)$ & $(33.800)$ & $(16.051)$ & $(20.776)$ & $(22.678)$ \\
\hline \multirow[t]{2}{*}{ GOVMODL } & $-1.365^{* * *}$ & $-1.266^{* * *}$ & $-0.941^{* * *}$ & $-0.507^{* * *}$ & $-0.753^{* * *}$ & $-0.919^{* * *}$ \\
\hline & $(-66.441)$ & $(-20.554)$ & $(-9.519)$ & $(-4.580)$ & $(-26.221)$ & $(-24.161)$ \\
\hline \multirow[t]{2}{*}{ COLLSTD } & $-0.0001^{* * *}$ & $-0.0001^{* * *}$ & $-0.0001^{* * *}$ & $-0.00004^{* * *}$ & $-0.0001^{* * *}$ & $-0.0001^{* * *}$ \\
\hline & $(-39.895)$ & $(-20.621)$ & $(-22.177)$ & $(-8.689)$ & $(-49 \cdot 535)$ & $(-13 \cdot 559)$ \\
\hline YEAR & YES & YES & YES & YES & YES & YES \\
\hline Adj. $R^{2}$ & 0.954 & 0.919 & 0.853 & 0.853 & 0.918 & 0.854 \\
\hline$F$ & $180.232^{* * *}$ & $98.775^{* * *}$ & $50.775^{* * *}$ & $50.889^{* * *}$ & $96.673^{* * *}$ & $51.167^{* * *}$ \\
\hline N & 87 & 87 & 87 & 87 & 87 & 87 \\
\hline
\end{tabular}

Note: $* * *, * *$ or $*$ indicates that the coefficient estimate is significant at the $1 \%, 5 \%$, or $10 \%$

Table 4 reports the regression results of the relationship among science and technology innovation, negative social mentality and economic growth from the perspective of 
individual negative emotions. The estimated coefficients on stress (STRESS), gloom (GLOOM), anxiety (ANXIETY), quick success (QBENFT), and anger (ANGER) are significantly negative, while the estimated coefficients on indifference (INDIFER) is not significantly negative, pointing that negative social mentality conveys "negative energy" and has a negative emotional impact on the participants in social and economic life so that negative emotions present to be harmful to the prosperity and development of regional economy. The estimated coefficients on the interaction terms between LTECH and four negative social mentality variables (STRESS, ANXIETY, INDIFER, ANGER and QBENFT) are all significantly negative, while the interaction coefficient of gloom and science and technology innovation (LTECH×GLOOM) is not significantly negative. The regression results above formulate that negative social mentality such as stress, anxiety, indifference, anger and quick success in social life has an adverse effect on the thoughts and behavior of social participants and provides false references for social groups. And negative social mentality would gradually develop into negative social sentiments that could be widely circulated and adversely affect science and technology innovation activities, weakening the supporting role of science and technology innovation in economic growth and the long-term stable development of economic society.

Table 5 describes the regression results of the relationship among science and technology innovation, negative social mentality and economic growth from the perspective of rich second generation. The estimated coefficients on five variables that characterize the rich second generation, including RCSCGN, SHOWOF, GFS, FUMBLA, and DADKY, are significantly negative. The results state that wealth-flaunting behavior of rich second generation has formed a bad social atmosphere in economic society, stimulated the worship mentality or hatred of rich people, intensifying social contradictions to a certain extent and thus affecting economic growth. The estimated coefficients on the interaction terms between LTECH and three negative social mentality variables (RCSCGN, SHOWOF and DADKY) are all significantly negative, while the estimated coefficients on the interaction terms between $\mathrm{LTECH}$ and the remain variables (GFS and FUMBLA) are not significant. Thus, the regression results indicate that the attention of the local netizens to the rich second generation, behavior of flaunting wealth, and competition of family background, to some extent, reflects envy from ordinary people to persons who rely on their family power to obtain money, status, opportunities, etc. And the accumulating passive thoughts that ordinary people could not succeed in their own efforts will finally transform to hatred of the wealthy and thus have a negative impact on the innovation efficiency of R\&D personnel, impairing the support of science and technology innovation in economic growth.

\section{Robustness Test:}

In order to ensure the credibility of the regression results, this paper tests the regression results from the perspective of measurement of variables, test of regulatory effects and processing of endogenous problems. The conclusions obtained from the test are basically consistent with the existing conclusions. 
Table 5 Science and technology innovation, Negative Social Mentality and Economic Growth: Perspective on Rich Second Generation

\begin{tabular}{|c|c|c|c|c|c|}
\hline & (1)RCSCGN & (2)SHOWOF & (3)GFS & (4)FUMBLA & (5)DADKY \\
\hline \multirow[t]{2}{*}{ C } & $0.746^{* * *}$ & $0.528^{* * *}$ & $0.589^{* *}$ & $0.594^{* * *}$ & $0.583^{* * *}$ \\
\hline & $(5.552)$ & (7.143) & (5.991) & $(5.493)$ & (15.043) \\
\hline \multirow[t]{2}{*}{ LTECH } & $0.074^{* * *}$ & $0.024^{* * *}$ & -0.001 & 0.008 & $0.056^{* * *}$ \\
\hline & $(3.376)$ & $(4.646)$ & $(-0.167)$ & $(0.762)$ & (13.343) \\
\hline \multirow[t]{2}{*}{ PASSIVE } & $-0.002^{* * *}$ & $-0.001^{* * *}$ & $-0.001^{* * *}$ & $-0.001^{* * *}$ & $-0.003^{* * *}$ \\
\hline & $(-3.684)$ & $(-4.815)$ & $(-2.729)$ & $(-3.592)$ & $(-7.329)$ \\
\hline \multirow[t]{2}{*}{ LTECH $\times P A S S I V E$} & $-0.0003^{* * *}$ & $-0.0002^{* * *}$ & 0.00003 & -0.00001 & $-0.001^{* * *}$ \\
\hline & $(-3.067)$ & $(-9.740)$ & (1.154) & $(-0.215)$ & $(-5.252)$ \\
\hline \multirow[t]{2}{*}{ PERCAP } & $0.001^{* * *}$ & $0.001^{* * *}$ & $0.001^{* * *}$ & $0.001^{* * *}$ & $0.001^{* * *}$ \\
\hline & $(3.320)$ & (4.143) & $(2.973)$ & (3.523) & (3.498) \\
\hline \multirow[t]{2}{*}{ INDUS } & $0.490^{* * *}$ & $0.667^{* * *}$ & $0.589^{* * *}$ & $0.675^{* * *}$ & $0.608^{* * *}$ \\
\hline & $(6.123)$ & (7.911) & $(4.687)$ & $(6.679)$ & $(7.086)$ \\
\hline \multirow[t]{2}{*}{ FORNT } & $0.837^{* * *}$ & $0.795^{* * *}$ & $0.876^{* * *}$ & $0.814^{* * *}$ & $0.834^{* * *}$ \\
\hline & (33.879) & $(28.932)$ & $(13.563)$ & $(54.916)$ & $(37.468)$ \\
\hline \multirow[t]{2}{*}{ GOVMODL } & $-0.765^{* * *}$ & $-0.772^{* * *}$ & $-1.012^{* * *}$ & $-0.867^{* * *}$ & $-0.713^{* * *}$ \\
\hline & $(-5.297)$ & $(-17.945)$ & $(-6.982)$ & $(-11.349)$ & $(-10.937)$ \\
\hline \multirow[t]{2}{*}{ COLLSTD } & $-0.0001^{* * *}$ & $-0.0001^{* * *}$ & $-0.0001^{* * *}$ & $-0.0001^{* * *}$ & $-0.00005^{* * *}$ \\
\hline & $(-42.731)$ & $(-19.527)$ & $(-10.962)$ & $(-19.951)$ & $(-12.251)$ \\
\hline YEAR & YES & YES & YES & YES & YES \\
\hline Adj. $R^{2}$ & 0.867 & 0.846 & 0.930 & 0.850 & 0.855 \\
\hline$F$ & $57.106^{* * *}$ & $48.241^{* * *}$ & $115.154^{* * *}$ & $49.870^{* * *}$ & $51.824^{* * *}$ \\
\hline$N$ & 87 & 87 & 87 & 87 & 87 \\
\hline
\end{tabular}

Note: $* * *, * *$, or * indicates that the coefficient estimate is significant at the $1 \%, 5 \%$, or $10 \%$ level, respectively.

\section{Measurement of Credit Construction:}

This study uses variables such as the establishment of credit websites (ESTAB), credit news (AFFAIR), credit policy (POLICY), credit publicity (HONE, DIHONE) to analyze the relationship among science and technology innovation, credit construction and economic growth. The existing regression results show that the impact of credit news and credit policies on the efficiency of science and technology innovation is not obvious. While in the robustness test, this paper further divides credit news (AFFAIR) into local credit news (LOCAFF), other regional credit news (CIVAFF) and international credit news (INTAFF), and classifies credit policy (POLICY) into local credit policy (LOCPOL), other provincial credit policy (OTHPOL), and national credit policy (CIVPOL). 
The average nature logarithms of LOCAFF, CIVAFF and INTAFF published on credit websites are 4.579, 5.663, and 3.632, respectively. And the absolute values of them are about 282, 600 and 57, indicating that credit websites tend to announce mostly of credit news of other regions and the least of international credit news. For credit policy, the average nature logarithms of LOCPOL, OTHPOL and CIVPOL are1.803, 2.141 and 2.296, corresponding to the absolute values of 7, 8 and 14. The values present that central government announces much more credit policies than the local does.

The regression results prescribe that local credit news (LOCAFF) are significantly positively correlated with economic growth, while the remaining variables are not significant. And the insignificant impact of credit news on the efficiency of science and technology innovation might stems from low popularity of credit news. The credit news announced by regional credit websites mainly involves the status of regional credit construction, advocacy or study for credit construction by various administrative agencies, and meetings related to credit construction. For example, the credit news released by the Credit China in 2016 includes the following: The CSRC (China Securities Regulatory Commission) publishes statistics and analysis results on the credit status of the capital market in 2015 according to the data of the Capital Market Integrity Database; the SAIC (State Administration for Industry and Commerce) announces the 2014-2015 "contract-honoring and credit-keeping" lists of enterprises. In general, most of the contents of credit news are circulated among administrative agencies, or focus on the analysis and reports of credit construction. These activities are relatively lacking in circulation among ordinary peoplein social life and thus have a weak promotion on regional economic growth.

In terms of credit policy, the estimated coefficient on the interaction term between LTECH and national credit policy (CIVPOL) is significantly positive, while the estimated coefficients on the interaction terms between $\mathrm{LTECH}$ and other variables are not significant. The weak influence of credit policy on the efficiency of science and technology innovation may be due to the fact that regional credit construction is in its infancy, that the number of relevant laws and regulations is small, and that the targeted groups of credit policy are relatively narrow. People generally do not pay much attention to credit issues when they are not punished for credit violations.

\section{Variables of Negative Social Mentality:}

Here we use Baidu Index to measure negative social mentality. The regression results verify the negative impact of negative social mentality on the efficiency of science and technology innovation. In order to enhance the reliability of regression results, this paper employs CGSS data to select frustration (UPSET) and profit at other's expense (EXTRSDV) as alternative variables for negative social mentality.

According to CGSS's research questions about "frustration" such as "Have you ever been troubled by some emotional problems (such as anxiety, depression or irritability) in the last month?" or "In the past four weeks, what was the frequency of your feeling depressed or frustrated.", we assign the respondents' answers with values of 1, 2, 3, 4 and 5. For instance, "completely no" or "never" is assigned a value of 1 and "very little", "sometimes" or "a little frustrated" , "often" or "very frustrated" and "very frequent" or "very frustrated" are accordingly assigned with values of 2, 3, 4 and 5. Calculating the mean value of respondents' depression in each region annually, we get the variable 
UPSET. And the higher the value of UPSET is, the more frustrated the people in the area feel.

Besides, CGSS's research questions about "profit at other's expense" is "In general, do you agree that in the society, if you are not careful, others will find a way to take advantage of you.". And the assignment for the answers "completely disagree", "comparatively disagree", "not agree or disagree", "comparatively agree" and "completely agree" are 1, 2, 3, 4, and 5. After formulating the average value of "profit at other people's expense" behavior in each region each year, we obtain the variable EXTRSDV. And the larger the value of EXTRSDV is, the more common the phenomenon of gain extra advantages by unfair means in society tend to be.

In light of the annual changes in CGSS research questions and answer options, the data range for frustration (UPSET) is in the year of 2005, 2010, 2011, 2012 and 2013, and the data on EXTRSDV covers the year of 2010, 2011, 2012 and 2013. The average value of UPSET is 2.15, indicating that regional respondents rarely feel depressed or frustrated on average and they hold a much positive social attitude. The mean value of EXTRSDV is 3.02, which indicates that the local people maintain in a state of not agreeing and disagreeing with the behavior of taking advantages of other people.

The regression results indicate that the estimated coefficient onUPSET is insignificant positive, while the estimated coefficient on EXTRSDV is significant negative. And the estimated coefficients on the interaction terms between LTECH andtwo variables (UPSET and EXTRASDV) are significant negative. Moreover, the regression results further validate the negative impact of negative social mentality on economic growth and the considerable weakening effect on the efficiency of science and technology innovation.

\section{Moderating Effects}

This paper, with interaction terms, examines regulatory effects of credit construction and social mentality in the relationship between science and technology innovation and economic growth. In order to enhance the robustness of regression results, we further discuss the moderating effects by using two sub-samples according to the medians of credit construction and social mentality variables. We exert regression analysis on the two sub-samples. Taking credit construction as an example, except for the virtual variable credit websites establishment (ESTAB), we divide regions into credit-friendly areas and credit-poor areas according to the median of each credit construction variable and respectively carry out retest of the relationship between science and technology innovation and economic growth. For the credit websites establishment (ESTAB) variable, it is directly classified into two sub-samples: area where the credit website is established and the area where the credit website is not established. Then this research separately re-examines the regression results of the efficiency of science and technology innovation. Overall, the regression results obtained are basically consistent with the existing conclusions.

\section{Endogenous problems}

In view of the potential endogenous problems between science and technology innovation and economic growth, this paper establishes the following simultaneous 
equation models to re-examine the relationship between science and technology innovation and economic growth.

$$
\begin{aligned}
\text { PREGDP }_{i t}= & f+w_{1} \text { TECH }_{i t}+w_{2} \text { PERCAP }_{i t}+w_{3} I N D U S_{i t}+w_{4} F O R N T_{i t}+w_{5} G O V M O D L_{i t} \\
& +w_{6} \text { COLLSTD }_{i t}+\mathrm{a} Y E A R+e \\
\text { TECH }_{i t}=c & +m_{1} \text { PERGDP }
\end{aligned}
$$

Where, TECH represents the science and technology innovation variable. We employ principal component analysis method to synthesize a composite index of 18 indicators just like the way to treat LTECH. However, the difference is that LTECH is a lagged variable and TECH is a current variable. RD symbolizes material capital investments of private sectors in R\&D activities and it is measured by the differences between total funding for scientific and technological activities and the part from governmental funds. The data are manually collected from China Statistical Yearbook of Science and Technology. KNOWL represents the accumulation of knowledge stock, which is measured by cumulative patents; FDI represents the technology spillover effect of foreign direct investment (FDI), measured by the amount of foreign direct investment. These data are collected manually from China Statistical Yearbook. And the remaining variables are consistent with model (1). The regression results of the simultaneous equations once again validate the significant driving effects of science and technology innovation on economic growth.

\section{CONCLUSION}

Using data on science and technology innovation, based on the dimension of social factor which concludes the credit construction, positive social mentality, and negative social mentality, this paper explores the impact of science and technology innovation environment on regional economic growth. The results show that the regional science and technology innovation has the function to boost local economic development. The establishment of regional credit websites, publicity of trustworthy behavior and untrustworthy behavior have improved the regional credit status, being conducive to fostering the credit awareness of social groups, encouraging R\&D personnel to innovate in good faith, and significantly enhancing the driving effect of science and technology innovation on economic growth. The weak influence of credit news and credit policy on the efficiency of science and technology innovation may result from the fact that credit construction in China is still in its primary stage, the credit news is relatively lacking in circulations among social groups, and the range of target audience of credit policy is relatively narrow.

When local netizens pay high attention to fairness, happiness and belief, they would feel that their life are much happy and are disposed to trust each other. This situation will promote the positive effect of regional science and technology innovation on local economic growth. Positive social mentality could make the prevalent values among social groups in social interaction become the mainstream mentality of the society through the sharing of reality, inter-subjectivity consensus and the characteristics of social representation in order to guide the dissemination of "positive energy" in society, which would play a great role in improving the efficiency of science and technology innovation. The negative social mentality such as pressure, anxiety, indifference, anger and quick success in social life has formed a wrong guidance for the thoughts and behavior of R\&D personnel, the influence can adversely affect the science and 
technology innovation activities and inhibited the supporting role of science and technology innovation. When local Internet users pay close attention to issues of rich second generation, behavior of flaunting wealth, and competition of family background, they tend to be disappointed with the fact of lacking social resources and in the long run this kind of emotion would be transformed into strong hatred of the rich. And all these social backgrounds will have a negative impact on the innovation enthusiasm of R\&D staff, thus weakening the strength of science and technology innovation on economic growth.

Practices have shown that the prosperity and development of regional economy depends on the local science and technology innovation environment, but local governments cannot ignore the potential impact of regional credit construction and social mentality on the efficiency of science and technology innovation. The regional governments should strengthen the formulation of credit policies and regulations, standardize the credit information platform and credit service market, and establish credit rewards and punishment linkage mechanism to promote traditional virtues of honesty and trustworthiness and further develop the sound social credit system. Combined with propagation characteristics of social emotions in the information age, governments should focus on leading positive social mentality to function as the mainstream ideology of the society, conducting regular and comprehensive social surveys, paying attention to online public opinions, and properly channeling the negative emotions that hinder the healthy development of social mentality.

\section{REFERENCES}

Temple, J., Johnson, P. A. (1998). Social capability and economic growth.Quarterly Journal of Economics, Vol.113No.3, pp.967-990.

Solow, R. M. (1956). A contribution to the theory of economic growth.Quarterly Journal of Economics, Vol.70No.1, pp.65-94.

Romer, P. M. (1986). Increasing returns and long-run growth.Journal of Political Economy, Vol.94No.5, pp.1002-1037.

Lucas, R. E. (1988). On the mechanics of economic development.Journal of Monetary Economics, Vol.22No.1, pp.3-42.

Carlin, B. I. (2009). Strategic price complexity in retail financial markets.Journal of Financial Economics, Vol.91No.3, pp.278-287.

Zak, P. J., Knack, S. (2001). Trust and growth.Social Science Electronic Publish, Vol.111No.470, pp.295-321.

Putnam, R. D., Leonardi, R., Nonetti, R. Y. (1994). Making democracy work: Civic traditions in modern Italy.Princeton: Princeton University Press.

Greeven, M. J. (2004). The evolution of high-technology in China after 1978: Towards technological entrepreneurship. ERIM Report Series Research in Management.

Zhang, G., Peng, X. B., Li, J. (2008). Technological entrepreneurship and policy environment: a case of China. Journal of Small Business and Enterprise 
Development,Vol.15No.4, pp.733-751.

Zhou, Q., Zhu, D., Ren, L. Q. (2012). Regional technical innovation suitability and economic growth in China.International Journal of Innovation and Sustainable Development,Vol.6No.4, pp.441-452.

Fan, S. M., Yan, J. J., Sha, J. H. (2017). Innovation and economic growth in the mining industry: Evidence from China's listed companies.Resources Policy, Vol.54No. 4, pp.25-42.

Xie, X. (1999). Economic Integration and Economic Growth with Science-Pushed Industrial Innovation.Review of International Economic. Vol.7No.4, pp.613-624.

Yuan, C. Q., Liu, S. F. Yang, Y. J., Shen, Y. (2016). On the contribution of defense innovation to China's economic growth.Defence and Peace Economics,Vol.27No.6, pp.820-837.

Kanygin, lu. M. (1976). Scientific-technical potential and long-term economic growth.Problems of Economics,Vol.18No.10, pp.23-48.

Weng, L.; Song, W., Sheng, S. B. (2012). Empirical research on scientific and technical innovation and economic growth in Shanghai.American Journal of Operations Research, Vol.2No.1, pp.82-9o.

Shan, S. Q., Jia, Y. W.,Zheng, X. R., Xu, X. B. (2018). Assessing relationship and contribution of China's technological entrepreneurship to socio-economic development.Technological Forecasting and Social Change.Vol.135No.10, pp.83-90.

Richard, E. C. (1974). Multinational firms, competition, and productivity in host-country markets.Economica,Vol.41No.162, pp.176-193.

Ding, C., Li, J. Y. (2014). Analysis over factors of innovation in China's fast economic growth since its beginning of reform and opening up.Al and Society, Vol.29No.3, pp.377386.

Guo, H., Hu, J., Yu, S., Sun, H., Chen, Y. (2012). Computing of the contribution rate of scientific and technological progress to economic growth in Chinese regions.Expert Systems with Applications, Vol.39No.10, pp.8514-8521.

Leser, C. E. V. (1967). Measurement of technical progress within scope of a comprehensive economic growth process-German-Fleck, FH.Journal of the Royal Statistical Society Series A (General), Vol. 130No.4, pp. 558-585.

Sanidas, E. (2004). Technology, technical and organizational innovations, economic and societal growth.Technology in Society, Vol.26No.1, pp.67-84.

Zhuo, L., Lu, Y., Deng, X. X. (2015). Study on the contribution rate of scientific and technological progress to economic growth in a coal enterprise. Proceedings of the Ninth International Conference on Management Science and Engineering Management, pp.1319-1328 